\title{
Erratum zu: Bedürfnisse und Arbeitsmotivation
}

\section{Erratum zu: F. Strotebeck, Einführung in die Mikroökonomik, https://doi.org/10.1007/978-3-658-27307-1_6}

Die Tabelle (Tab. 6.1) wurde korrigiert zu:
Sie
C D
$\begin{array}{llll}\text { Ich } & \text { C } & \text { v } \mid v & y \mid z \\ & D & \text { z } \mid y & \text { w } \mid w\end{array}$

Die aktualisierte Version der Titeleiseiten dieses Buches finden Sie unter https://doi.org/10.1007/978-3-658-27307-1_6

(C) Springer Fachmedien Wiesbaden GmbH, ein Teil von Springer Nature 2020 